\title{
The feasibility of a custom-made endoprosthesis in mandibular reconstruction: Implant design and finite element analysis
}

\author{
Manuel Pinheiro*, J.L. Alves \\ Department of Mechanical Engineering, University of Minho, Guimarães, Braga, Portugal
}

\section{A R T I C L E I N F O}

Article history:

Paper received 17 June 2015

Accepted 2 October 2015

Available online 20 October 2015

\section{Keywords:}

Cephalometry

Endosseous implantation

Mandibular reconstruction

Mandibular prosthesis implantation

Finite element analysis

\begin{abstract}
A B S T R A C T
This work studies the feasibility of custom-made endoprosthesis in the reconstruction of major mandibular defects. The natural anatomical and occlusal relations are used to accurately reconstruct a mandibular defect. The customized implant allows the accurate restoration of the facial profile and aesthetics. The biomechanical behaviour of mandibular endoprosthesis was validated with Finite Element Analysis for three masticatory tasks, namely incisal, right molar and left group clenching. The implanted mandible shows displacement fields and stress distributions very similar to the intact mandible. The strain fields observed along the bone-implant interface may promote bone maintenance and ingrowth. The preliminary results show that this implant may be a reliable alternative to other prosthetic mandibular reconstruction approaches.
\end{abstract}

(c) 2015 European Association for Cranio-Maxillo-Facial Surgery. Published by Elsevier Ltd. All rights reserved.

\section{Introduction}

Mandibular reconstruction is often needed to compensate bone loss related with trauma, inflammatory disease, and benign or malignant tumours. Mandibular resection caused by malignant or aggressive odontogenic tumours can originate extensive defects on the orofacial cavity, including bone, oral mucosa, muscles, and teeth. The primary objective of a mandibulectomy is to remove all deceased tissues and provide quality of life to the patient. The surgical procedure should provide both functional and cosmetic rehabilitation (Peled et al., 2005; Goh et al., 2008; Flint et al., 2010). Therefore, orofacial reconstruction should restore the oral competency, maintain occlusal relationships between the remaining teeth, allows for prosthetic dental restoration, restore bone continuity and the contour of the lower third of the human face, as well as the facial symmetry (Taylor, 1982; Goh et al., 2008). The implanted material should provide sufficient height for adequate muscle attachment, provide the possibility for dental implant insertion, and allow the restoration of the normal occlusion and articulation of the mandible (Goh et al., 2008).

\footnotetext{
* Corresponding author. Department of Mechanical Engineering, Escola de Engenharia - Universidade do Minho, Campus de Azurém, 4804-533 Guimarães, Portugal. Tel.: +351934074020.

E-mail address: manuelspinheiro@gmail.com (M. Pinheiro).
}

During mandibular reconstruction considerable amounts of soft and hard tissue may be needed for the complete rehabilitation of the lower facial region. The most common donor sites are the iliac crest, the radius forearm, the scapula, and the fibula (Peled et al., 2005). Each donor site differs in the quality and quantity of bone and soft tissue available; in the quality of the vascular pedicle; in the possibility of bone reshaping and placement of dental implants in a second stage surgery (Goh et al., 2008). The fibular flaps and the iliac flaps provide the most suitable bone stock for dental rehabilitation, and are preferred over other donor sites (Miloro et al., 2004). The microvascular free flaps are currently seen as the gold standard for mandibular reconstruction.

The first microvascular free fibular bone flap transfer was reported in Hidalgo (1989), and was used to reconstruct a segmental defect on the mandible. This technique has revolutionized oromandibular reconstruction, since it enabled a compound graft to be transferred from the donor site with bone and soft tissue, without damaging their own vascular supply, to the head and neck regions (Bak et al., 2010). Success rates near 100\% have been reported with this technique, even in the treatment of the most adverse situations (Gurtner and Evans, 2000). Currently, free microvascular flaps are used to reconstruct large mandibular defects (Haughey et al., 1994), where there is inadequate soft tissue or the recipient site has already been subjected to radiation (Östrup and Fredrickson, 1975), to manage chronic infections, to correct previous surgeries, and in primary mandibular reconstruction due to aggressive odontogenic tumours (Disa and Cordeiro, 2000; Peled et al., 2005). 
Free microvascular fibular reconstruction has numerous advantages against other microvascular free flap techniques. Nevertheless, this procedure cannot be performed in patients that have deficient lower limb vascularization. For instance, patients with ischaemic diseases of the lower limbs, arteriosclerosis, small length of the fibula pedicle, and limited thickness of the soft tissue are not eligible for this type of mandibular reconstruction (Ferri et al., 1997). As an alternative, several authors addressed mandibular reconstruction through the development of custom implantable devices. Custom devices aim to reduce the time and complexity of the surgical procedure, to enhance the aesthetic outcome, and to reduce or even eliminate the need for bone harvesting. Two types of custom-made implants may be identified: there are the titanium trays that shape and provide mechanical support to the bone grafts collected from one of the possible donor sites, for instance, the custom-made titanium trays proposed in Samman et al. (1999) and in Singare et al. (2004), and custom-made plates that use screws to fix the implant to the remaining mandible. In the second type of implants one can find the solutions proposed in Peckitt (1999) and in Li et al. (2014). More recently, the company Xilloc Medical BV documented the development and implantation of a complete custom-made mandibular implant, obtained from the patient's CT scan (Nickels, 2012).

A different approach for bridging a mandibular defect was proposed in Tideman (2006): an endoprosthesis composed by several modules and a screw-based locking system for the accurate mandibular reconstruction was proposed. The successful implantation of a cemented titanium alloy (Ti-6Al-4V) modular endoprosthesis in animals was reported in Lee et al. (2008). After 3 months of follow-up, there were no signs of implant loosening. There was no masticatory function loss and no signs of occlusion problems. Nevertheless, two of the modular endoprosthesis systems failed due to the screw connection between the different modules of the implant. The modular endoprosthesis concept was also applied to the ascending ramus and mandibular condyle by Goh et al. (2009b), as an alternative to the traditional temporomandibular joint replacement techniques. Normal temporomandibular joint function, mouth opening and occlusion were observed postoperatively.

One of the major problems associated with all the aforementioned custom-made implants is the failure of the screwed connections at the bone-implant interface. This problem has been widely described in the literature. Several authors concluded that plates fixed in the buccal aspect of the mandible have to withstand unfavourable forces that often lead to loosening of the screws and fracturing of the plates (Kim and Donoff, 1992; Spencer et al., 1999; Shibahara et al., 2002). In a finite element study, Knoll et al. (2006) concluded that masticatory loads and high chewing forces may lead to fatigue failure of the reconstruction plates and/or to screw loosening. A wider flat plate design with square screw configuration was proposed to bridge a mandibular angle defect and to minimize the stress concentration across the cortical bone and plate screws. Ramos et al. (2011) analysed the stress along custommade temporomandibular joint implants, and observed high detrimental mechanical stresses at the level of the first screw regardless of the implant geometry used to interface the mandibular bone. Similarly, Wong et al. (2012a,b) proposed a modular endoprosthesis with a different screwed configuration. High stress concentrations around the connecting screw and the stem caused the long term failure of the implant due to fatigue. The high tendency for transverse bending of the new modular design may also lead to implant loosening when treating large mandibular defects.

Microvascular free flap reconstruction is still the most beneficial approach to mandibular rehabilitation, and possesses many advantages to the patient that may be difficultly to match with other implantable or non-implantable approaches. Nevertheless, the modular endoprosthesis are also interesting and new solutions for mandibular reconstruction, because they may avoid screwed connections along the bone-implant interface. In this type of implants, modularity seems to be an issue, which increases the need for customization as a way to adapt to the specific anatomy of the user. In this work a custom-made mandibular endoprosthesis is developed. The proposed methodology aims to optimize the size and shape of the implant in order to enhance the functional and aesthetic outcome of the reconstructive surgery. The mandibular endoprosthesis is further validated with FEA under three different clenching tasks. The article is organized as follows: in section 2, image segmentation and implant design are overviewed; in section 3 , the Finite Element model and boundary conditions are described; in sections 4 and 5, the description and discussion of the FE results are presented, respectively; and in section 6 , the main conclusions are discussed.

\section{Material and methods}

The aim of this work is the development of a customized solution for the reconstruction of a major mandibular defect in a male subject caused by an extensive osteonecrosis along the anterior aspect of the mandible. In this section, the implant customization protocol from CT image data and the Finite Element modelling of the implanted mandible are described.

\subsection{Cephalometric assessment and implant modelling}

Bone segmentation from the CT image data was carried using the algorithm proposed in Pinheiro and Alves (2015). In Fig. 1 the segmentation process is overviewed. First, both the cranium, the facial bones, and the mandible were segmented by thresholding (Fig. 1 (a) and (b)). Next, a segmentation refinement step was applied to obtain an accurate description of the target regions of interest (Fig. 1 (c)). In the final model (Fig. 1 (d)) the complete bone loss from the chin to the level of the second molars is clearly observable. It can also be observed that both mandibular segments were rotated inward and upward relatively to their correct anatomical position.

In order to determine the accurate position of the chin and the dimensions of the lower third of the patient's face, a cephalometric assessment was carried. Cephalometric analysis is the study of the dental and skeletal relationships of the human head. It is commonly used by dentists and orthodontists to evaluate facial growth, as a tool for treatment planning in cases of abnormal development, or as an assessment method for treatment outcomes (Mitchell, 2013). The cephalometric analysis is based on the determination of the socalled Natural Head Position (NHP) (Moorrees and Kean, 1958). Commonly, the NHP is determined physiologically rather than anatomically, and it is the position that the head adopts when the patient is sitting or standing, looking to the horizon or at a distant object (Proffit et al., 2006; Cobourne and DiBiase, 2010). The NHP provides a common ground for the determination and correlation of several anatomical landmarks and planes, used to evaluate the craniofacial anatomy. In Fig. 2, the most common anatomical landmarks, lines and reference planes used in conventional 2D craniofacial cephalometry analysis are depicted.

The main goal of cephalometric analysis is to preserve both function and aesthetics. It is known that the position and shape of the mandible plays a major role in facial aesthetics, and it is the greatest source of facial asymmetry (Yáñez-Vico et al., 2011). The ideal face can be divided into equal thirds, namely the upper third, from the frontal hairline to the glabella, the middle third, from the glabella to the soft tissue of nasal base, and the lower third, from 

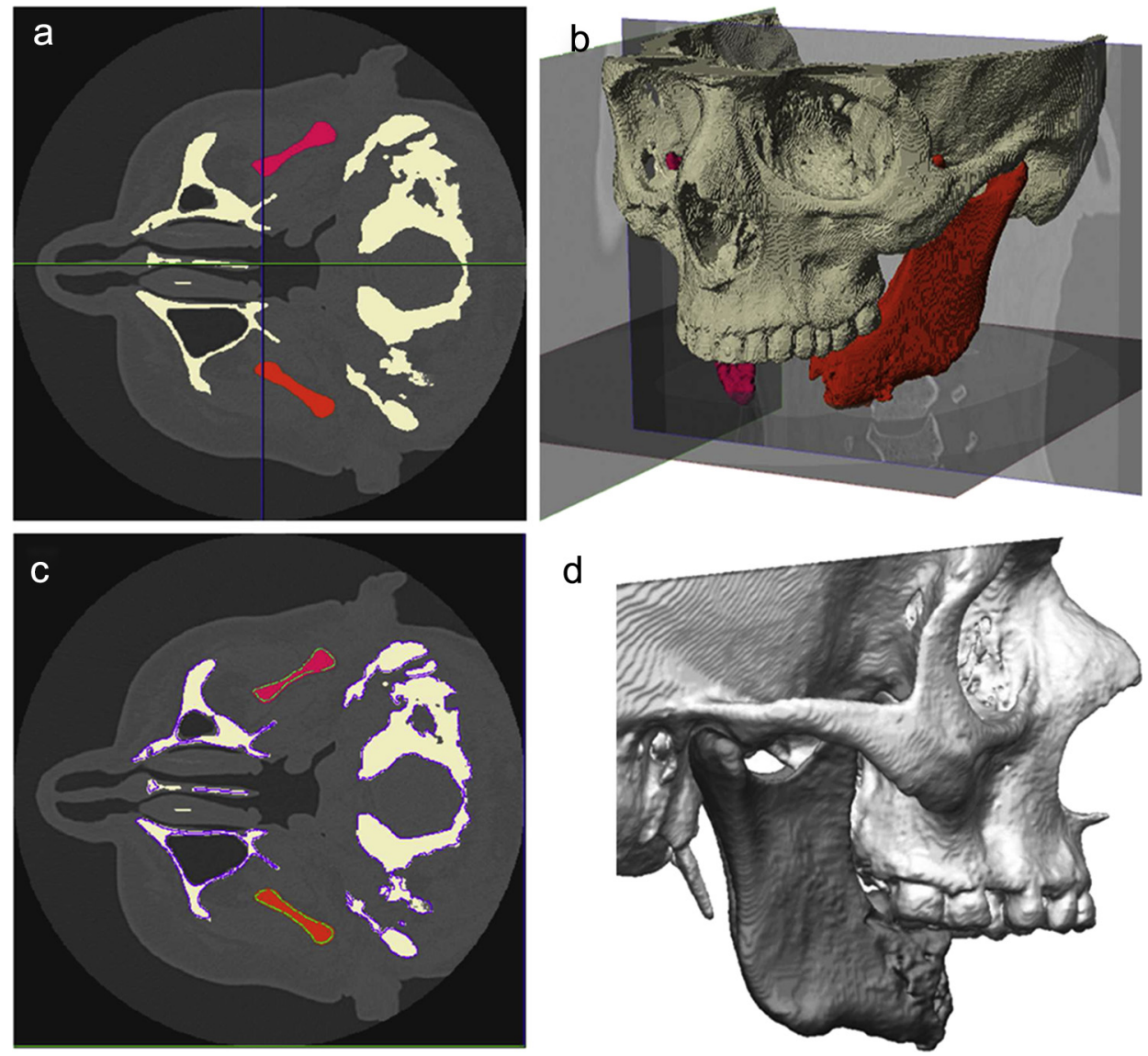

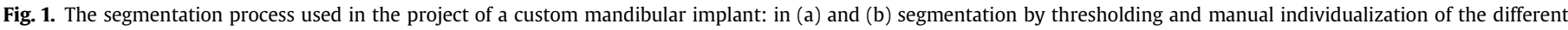

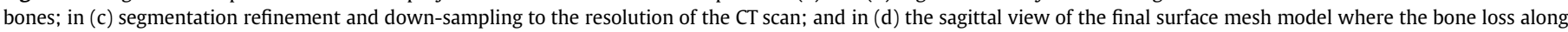
the mandibular body is clearly evident.

the nasal base to the lowest point on the chin (Fig. 2 (b) and (c)). The height of the facial middle third can be determined as the distance from the Nasion point (N) to the Subspinale point (A), whereas the lower third is defined as the distance from the point $A$ to the Me point (Athanasiou, 1995; Miloro et al., 2004; Flint et al., 2010; Sato et al., 2012). The facial lower third can be further divided into another thirds, being the upper lip in the upper third, and the lower lip on the remaining two thirds (Mitchell, 2013).

First, the NHP was approximated considering the cephalometric reference frame proposed in Lagravère et al. (2006). The reference frame is defined over five anatomical landmarks, namely the midpoint between geometric centres of foramina spinosum, left and right centre of the superior-lateral border of the external auditory meatus, and the midpoint of the foramen magnum (Fig. 3). To correctly define the position of the head, the FH must be defined as the true horizontal direction, or the McNamara line as the true vertical direction. The FH plane is very difficult to determine in practice (3D cephalometry). Both the Po and the Or landmarks are bilateral structures, and their determination is affected by the natural asymmetry of the head (Cobourne and DiBiase, 2010). In an ideal adult, the McNamara line lies $1.0-2.0 \mathrm{~mm}$ posterior to the A point, therefore the determination of this line is more straightforward than the FH plane (Meneghini and Biondi, 2012). The McNamara line has also the advantage of being defined by landmarks belonging to the mid-sagittal plane. This ensures consistency with the current reference frame, and allow us to define the correct 3D orientation of the head within the NHP frame. The head frame proposed in Lagravère et al. (2006) was adjusted to have the true vertical direction defined according to the McNamara line.
Next, each mandibular segment was rotated around the most superior point of each condylar process (SCo reference point), as defined in Hilgers et al. (2005). For occlusion correction, the Angle's Classification was considered. Based on this classification, system three types of malocclusion can be discriminated: Class I or neutroclusion: the mesiobuccal cusp of the upper first molar occludes with the mesiobuccal groove of the lower first molar; Class II or distoclusion - the mesiobuccal cusp of the lower first molar occludes distal to the Class I position; Class III or mesiocclusion - the mesiobuccal cusp of the lower first molar occludes mesial to the Class I position. According to the Angle's classification, a tooth-to-two-teeth relationship between the upper and lower teeth arches should exist (Fig. 4 (a)). In addition, a centric occlusion should be observed, i.e. the lingual upper molars cusps should occlude the lower molar fossa along the transverse (coronal) anatomical plane (Singh, 2008).

After defining the NHP and the proper position of both mandibular segments, cephalometric assessment may be performed to find the most plausible position of the chin. The mandibular plane was defined as the plane that best fits the lower border of the mandibular segments, whereas the posterior ramus plane was defined as the tangent plane to the posterior contour of the ramus (Fig. 4 (a)). Both planes were determined applying the Principal Component Analysis (Jackson, 2005). In the mid-sagittal plane, the projection of the mandibular plane and the McNamara line can be correlated to obtain the Gnathion (Gn) point (Fig. 4 (b)). In addition and considering the height of the mid and lower thirds of the human face, the Me point can be defined as the intersection of the mandibular line and an horizontal line perpendicular to the McNamara line $56.88 \mathrm{~mm}$ below the A point (Fig. 4 (b)). 
a

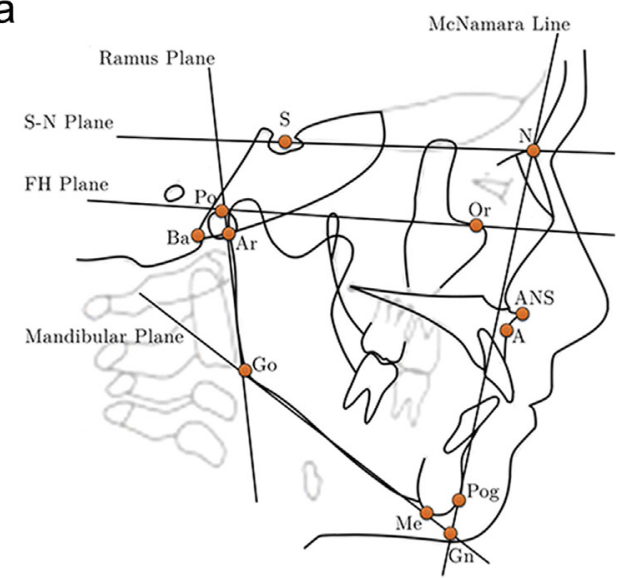

b

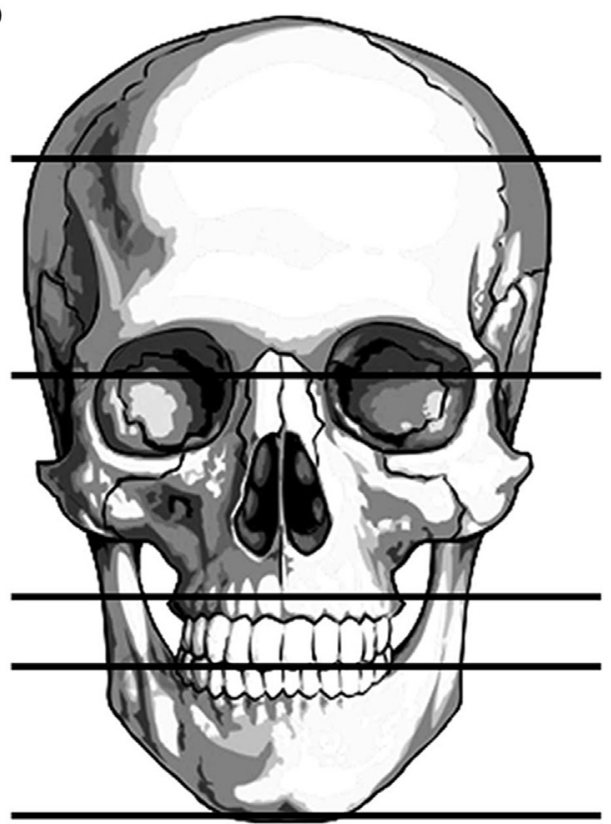

C

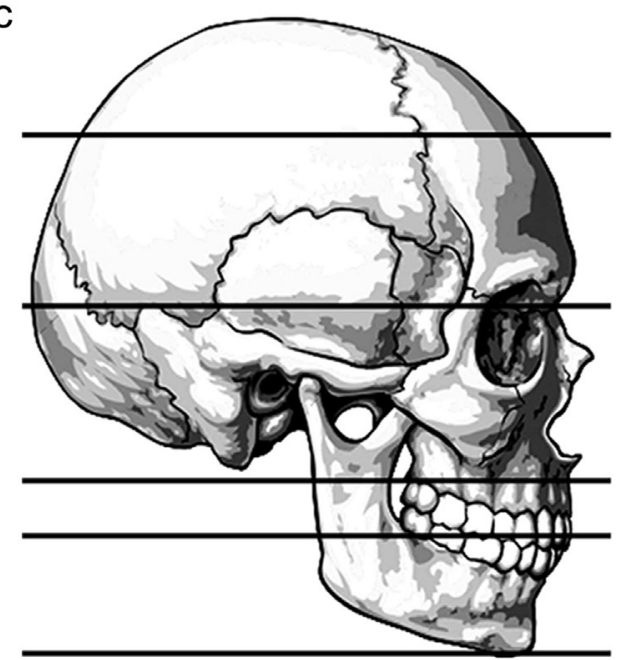

Fig. 2. (a) The anatomical landmarks and planes commonly used in cephalometric assessment: Nasion $(\mathrm{N})$ - the most anterior point of the frontonasal suture; Sella $(\mathrm{S})$ -
The McNamara line is, by definition, the line defined between the point $\mathrm{N}$ and the point Pog, the most prominent point of the chin. The Pog point is fundamental for understanding the anteroposterior positioning of the chin, and consequently the sagittal extent of the lower face. These three anatomical points (Me, Pog and $\mathrm{Gn}$ ) provide a rough estimate of the subjects' most plausible sagittal facial profile, and the correct position and height of the chin (Fig. 4 (b)). More insights on the shape of the chin may be obtained considering the spatial relations between the maxilla and the mandible according to the Angle's Classification and the Ballard's conversion. In neutrocclusion, the mandible is $2.0-3.0 \mathrm{~mm}$ posterior to the maxilla. In addition, according to the Ballard's conversion the lower incisor are commonly rotated relative to the mandibular plane about $88.5^{\circ}$. The lower teeth should also be positioned with a teeth overjet between 2.0 and $4.0 \mathrm{~mm}$ from the upper incisor. In addition, the vertical distance between the lower border of the maxillary incisors and the upper border of the lower incisor (overbite) should be approximately 2.0-3.0 mm (Mitchell, 2013). Given these additional anatomical relationships, the relative orientation and position of the lower incisor teeth can be estimated (Fig. 4 (b)). In Fig. 4 (c) the final geometry of the mandibular implant with a prosthetic device is depicted. The mandibular endoprosthesis takes into account the facial height, chin protrusion, and the oral rehabilitation after implantation. The weight of the solid implant is, for Ti-6Al-4V titanium alloy, of approximately $67.0 \mathrm{~g}$. In this early design, the dental superstructure is placed directly over four standard dental implants, positioned according to the All-on-Four system. In the All-on-Four technique, the two most anterior implants are typically placed immediately below the lateral or central incisors, and the two posterior implants emerge at the second premolar or second premolar/first molar region (Maló et al., 2003, 2005).

The mandibular implant has a stem geometry similar to the modular endoprosthesis proposed in Tideman (2006) and in Lee et al. (2008), aiming to recover more accurately the facial profile, enhancing facial aesthetics, and function of the masticatory system. As mentioned previously, the mandibular endoprosthesis may be advantageous against other prosthetic solutions, because it avoids the complications associated with reconstruction plates, such as the fracture and the detachment of the hardware, infection, bone resorption, and with microvascular flaps, such as the lack of bone volume to enable the placement of osseointegrated implants for oral rehabilitation (Goh et al., 2008; Knoll et al., 2006; Wong et al., 2012b). The trajectories of the forces applied to the mandible by fixation screws are different from the physiological forces caused by mastication. These unfavourable forces cause bone resorption

the centre of the pituitary fossa; Orbitale (Or) - the most inferior point on the lower border of the bony orbit; Porion (Po) - The most superior point of the external and internal auditory meatus; Articulare $(\mathrm{Ar})$ - the intersection point of the ramus plane and the occipital bone; Gonion (Go) - the intersection of the ramus plane and the mandibular plane; Menton (Me) - the most inferior point of the mentum section; Gnathion $(\mathrm{Gn})$ - the point on the chin determined by bisecting the angle formed by the facial and the mandibular plane; Pogonion (Pog) - the most prominent point of the chin; Subspinale $(A)$ - the deepest point on the concave outline of the upper labial alveolar process; Basion $(\mathrm{Ba})$ - The most inferior posterior point of the occipital bone at the anterior margin of the occipital foramen; Anterior Nasal Spine (ANS) - The most anterior point at the sagittal plane on the bony hard palate; Frankfort horizontal plane (FH) - A line connecting the Po and Or points; McNamara line - the line which passes through $\mathrm{N}$ and is perpendicular to $\mathrm{FH}$; SN plane - A line connecting the Sella and the Nasion points; Mandibular plane a tangent line to the lower border of the mandible; Ramus plane - a tangent line on the posterior contour of the ramus; (b) and (c) the ideal facial height division: the upper third between the from the frontal hairline to the glabella; the middle third from the glabella to the soft tissue of nasal base; and the lower third from the nasal base to the lowest point on the chin (adapted from (Athanasiou, 1995; Sato et al., 2012; Kawashima et al., 2002; Cobourne and DiBiase, 2010)). 


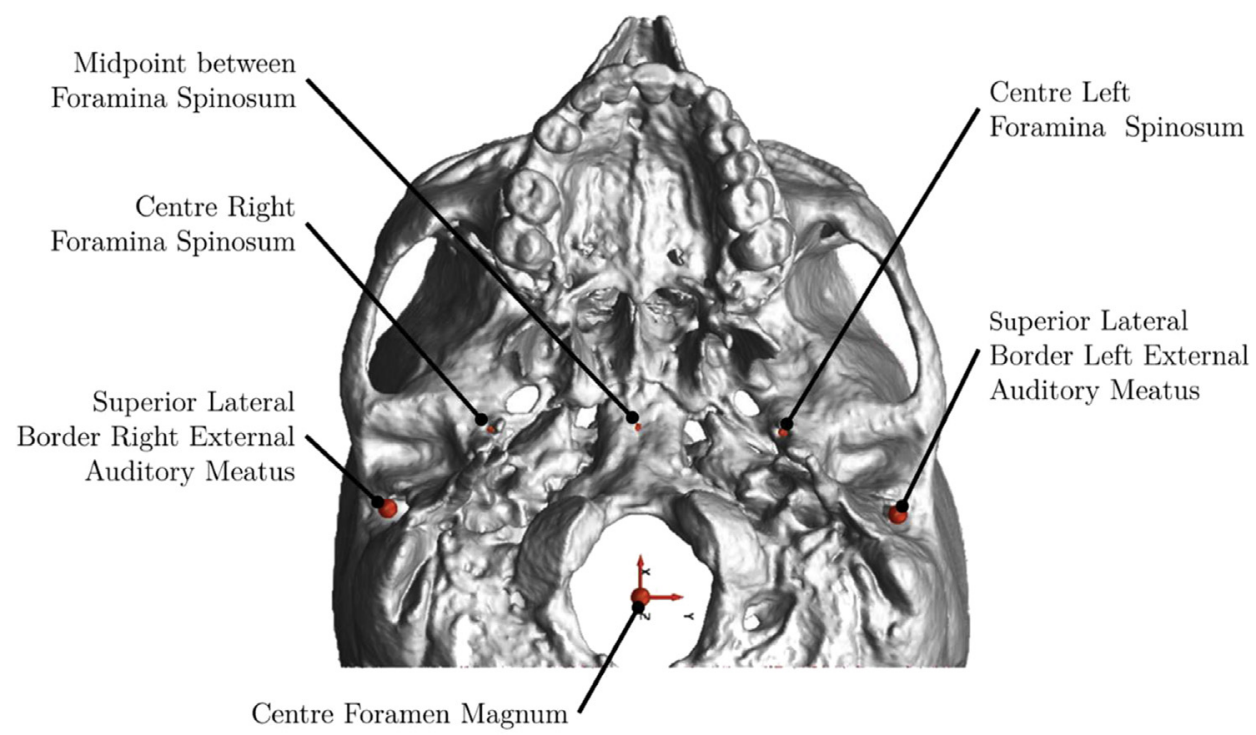

Fig. 3. Determination of the head reference planes according to the methodology proposed in Lagravère et al., (2006).

and are responsible for screw loosening over time, and the consequent loss of function observed in some temporomandibular replacements (Skedros et al., 1996; Spencer et al., 1999). Fig. 5 (a) and (b) depict the mandibular endoprosthesis proposed.

\subsection{Mandibular endoprosthesis finite element model}

To understand the mechanical behaviour of the proposed mandibular endoprosthesis, the implant was simulated under static clenching conditions. Simulations were carried according to the loading conditions defined in Korioth and Hannam (1994), in which the orthogonal directions, the muscle forces and the scaling factors for different clenching tasks are defined. The mastication tasks considered in this work are incisal clenching, unilateral molar clenching, and left group clenching, which involves the left canine, premolars and molar teeth.

The forces observed along the teeth arch have a large variability, and biting forces of more than $2200 \mathrm{~N}$ have been reported in the literature (Misch, 2007). Different bite forces have been reported for different teeth groups. However, the bite force is commonly larger at the first molar region, and reduces gradually towards the incisor teeth. For instance, Waltimo et al. (1993) measured an average bite force of $237 \mathrm{~N}$ in the incisors, and an average maximum bite force of $747 \mathrm{~N}$ in the molar region for male subjects, whereas for women an average maximum force of $204 \mathrm{~N}$ and $573 \mathrm{~N}$ were found along the frontal and molar teeth, respectively. Here, the bite forces for each individual clenching task were derived directly from single tooth measurements. The forces are based on the measurements found in Ferrario et al. (2004) and are summarized in Table 1.

According to Korioth and Hannam (1994), to simulate the different Human clenching movements, three major muscle groups must be considered, namely the masseter muscles, the temporalis muscles, and the pterygoid muscles (Fig. 6). Since for each clenching task muscle groups are recruited differently, a set of scaling factors to model the relative importance of each muscle group were also proposed. The single tooth forces in Table 1 (for male subjects) were scaled to produce the desired forces for each individual clenching task. The reaction forces along the teeth should be $570.90 \mathrm{~N}$ for incisal clenching, $600.40 \mathrm{~N}$ for right molar clenching, and $1336.10 \mathrm{~N}$ for the left side group clenching.
To predict the muscle forces required to produce the desired teeth reaction forces, an intact mandible model was segmented from elsewhere. The new (scaled) muscular forces were then applied to the implanted model to understand the stress and strain distribution along the right and left mandibular segments after endoprosthesis implantation. Table 2 summarizes the muscle forces for each masticatory activity needed to obtain the desired bite forces.

The Finite Element model of the intact mandible was generated with Simpleware +FE Module (available with Simpleware ScanIPT M v4.0), with 4-node tetrahedral element with varying edge length between $0.50 \mathrm{~mm}$ and $2.0 \mathrm{~mm}$. A Finite Element mesh with 27,590 nodes and 108,164 elements was obtained (Fig. 7 (a)). Next, the FE mesh was simplified internally with 50,000 as the minimum target number of elements, using the software simptets. ${ }^{1}$ Ultimately, the 4-node tetrahedral elements were converted into 10 -node tetrahedral elements by adding the intermediate nodes. The final mesh of the intact mandible is depicted Fig. 7 (b), and has 57,253 10-node tetrahedral elements and 113,417 nodes. Similarly to the intact mandible, a 4-node tetrahedral mesh of the implanted mandible was generated with Simpleware $+\mathrm{F}$ E Module. The implanted mandible has 54,642 nodes and 218,888 elements. After simplification and conversion (4-node to 10-node tetrahedra), the final FE mesh of the implanted mandible has 139,214 elements and 255,489 nodes (Fig. 7 (c) and (d)). The Finite Element Numerical simulations were performed using a home-developed solver named DD3IMP (Oliveira et al., 2008).

For FE simulation the right and left temporomandibular joints were restrained in all three directions. The teeth arch was also restrained vertically according to each simulated task, namely during incisal clenching (the four incisors were restrained from moving vertically), for right molar clenching (the first and second molars were restrained), and for left side group (the canine, the first and second premolars, and the first and second molars) were restrained vertically. The muscle forces were applied in a set of nodes at each muscle insertion site as shown schematically in Fig. 6. The mechanical properties of the Ti-6Al-4V alloy were assigned to the mandibular endoprosthesis: Young's modulus

\footnotetext{
1 http://vcad-hpsv.riken.jp/en/release_software/Simptets/.
} 

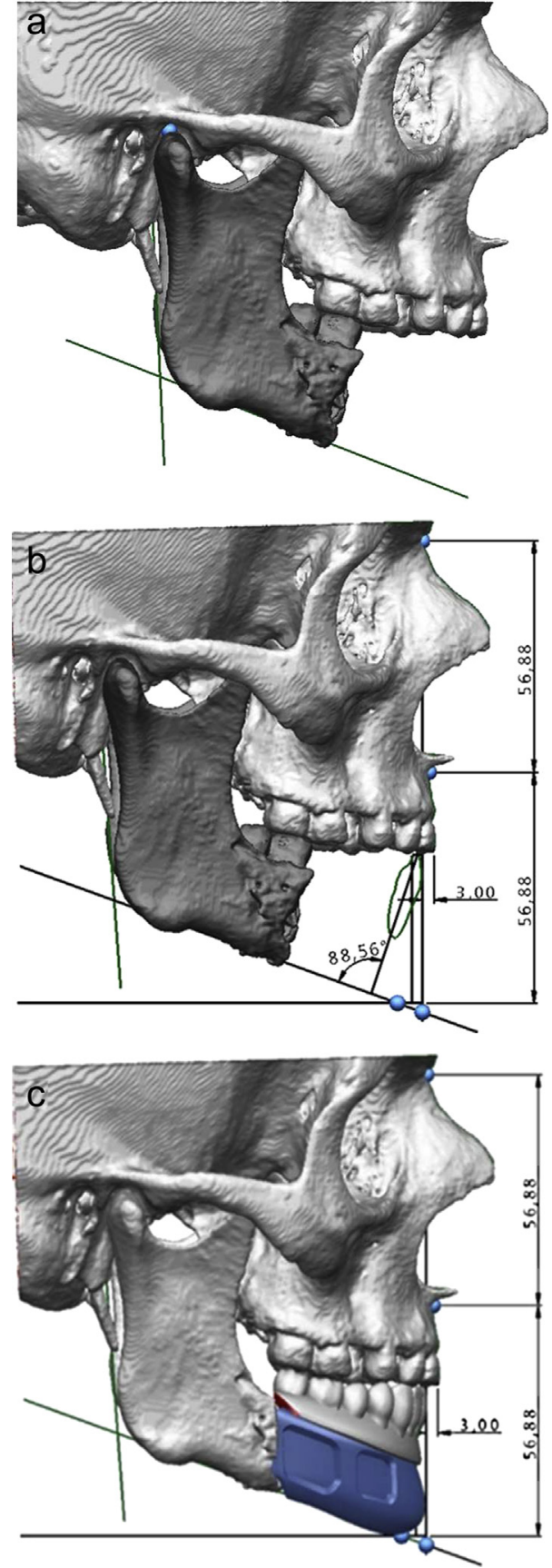

Fig. 4. (a) Restoration of the correct occlusion according to the Angle's Classification and determination of the posterior ramus plane and the mandibular plane; (b) the definition of the inferior and anterior limits of the chin and the position of the lower incisors according to the Ballard conversion; and (c) the preview of the mandibular endoprosthesis considering the previously defined cephalometric relations.

$\mathrm{E}=113800 \mathrm{MPa}$ and Poisson's Ratio of $v=0.34$. The dental prosthesis was assigned with the mechanical properties of a chrome-cobalt alloy: $\mathrm{E}=240000 \mathrm{MPa}$ and $v=0.30$. The mandible was modelled as being composed only by cortical bone and the elastic modulus $\mathrm{E}=13700 \mathrm{MPa}$ and $v=0.30$ were considered (Welsch et al., 1993; Van Oosterwyck et al., 1998; Bozkaya et al., 2004; Baggi et al., 2008). All materials were modelled as linear elastic, isotropic and homogeneous and all components totally bounded. a
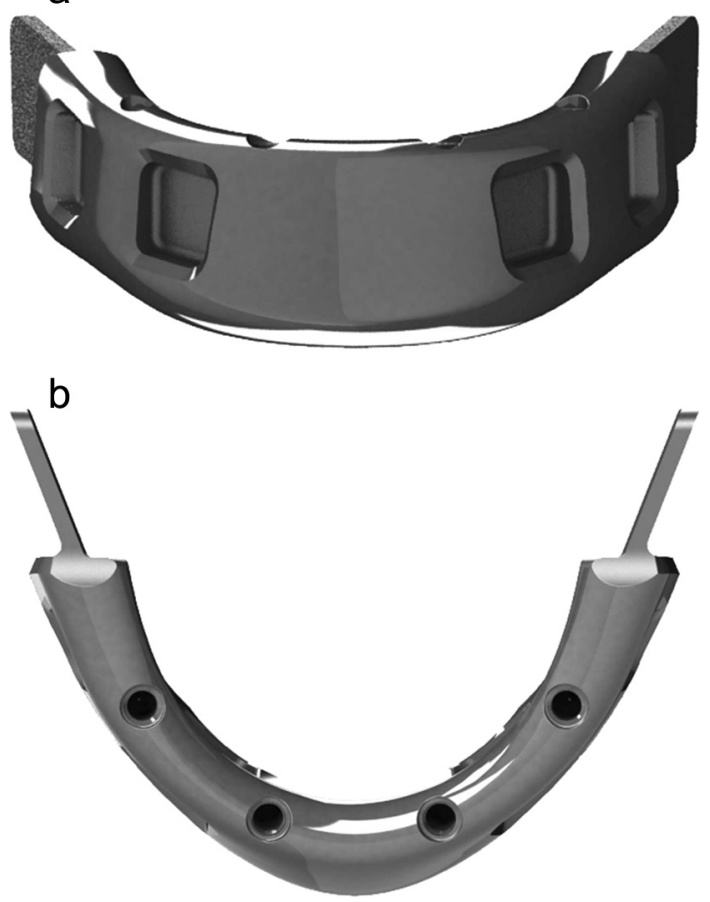

Fig. 5. (a) Coronal view and (b) top view of the Ti-6Al-4V mandibular endoprosthesis proposed and validated in this work.

\section{Results}

First, the transverse nodal displacement fields of the implanted mandible under the three different masticatory tasks were analysed (Fig. 8). Surface nodal displacements were assessed along a transverse cutting plane passing through the middle of the mandibular implant.

During incisal chewing, the right and left muscle groups are recruited equally, and therefore similar but symmetrical nodal displacements were observed on both sides of the mandible. In the transverse plane, the posterior mandibular nodes are mainly displaced inward. Nodal displacement gradually decreases when moving from the ascending ramus towards the chin. A slight rotation towards the right side was also observed in the anterior region of the implant (Fig. 8). In right molar clenching, the transverse nodal displacement along both sides of the mandible was minimal. The negative nodal displacement observed on both sides of the mandible also suggests that the implanted mandible is slightly moved towards the right. For left group clenching large nodal displacements were observed. The mandible was globally moved towards the left side, and the largest displacements were observed on the balancing side of the mandible when compared with the working side. This may be explained by the differences in

Table 1

Static single tooth clenching forces (in Newton) for young adults proposed in Ferrario et al. (2004).

\begin{tabular}{lcc}
\hline Tooth & Women & Men \\
\hline Central incisor & 93.88 & 146.17 \\
Lateral incisor & 95.75 & 139.30 \\
Canine & 119.68 & 190.31 \\
1st premolar & 178.54 & 254.08 \\
2nd premolar & 206.01 & 291.36 \\
1st molar & 234.46 & 306.07 \\
2nd molar & 221.71 & 294.30 \\
\hline
\end{tabular}




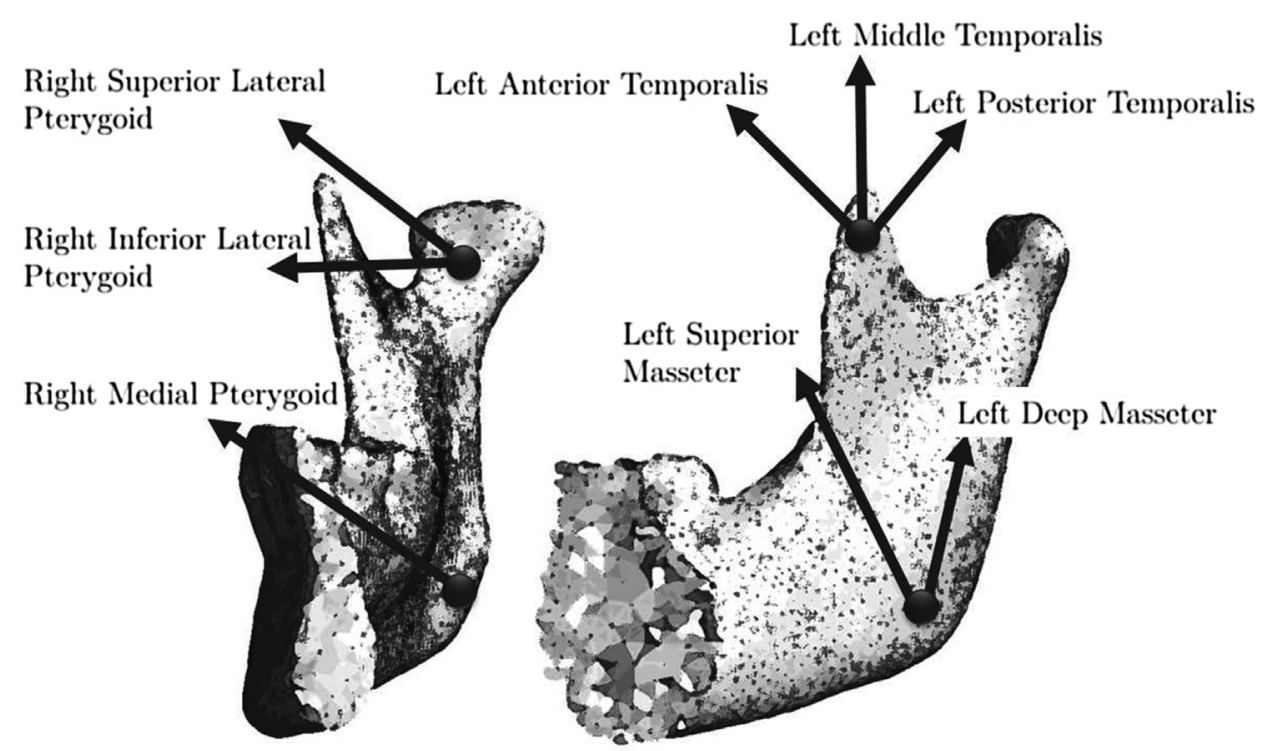

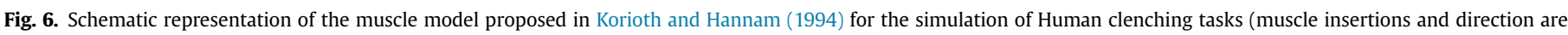
partly shown on the left and right mandible for simplicity).

muscle recruitment between the right and left medial Pterygoid during this particular task (see Table 2). In this direction the nodal displacements considerably decreases at the bone-implant interface (60 $\mathrm{mm}$ line in Fig. 8). This is evident in the transverse displacement field along the working side for left group clenching.

Fig. 9 depicts the craniocaudal and anteroposterior displacements of the mandible for the three masticatory tasks. In all tasks the mandible moves upward and forward. For incisal clenching, the vertical displacements are almost symmetrical relatively to the facial sagittal plane, and decrease towards the chin. The anterior displacement is relatively constant along the whole mandible. During right mandibular function, the proximal and anterior displacements are slightly larger on the left side of the mandible. Likewise, in left group clenching, the largest proximal displacements occur on the balancing side (right side). However, in left group clenching, the greatest anterior displacements occur on the loaded side (left side). The displacement fields indicate that in both unilateral chewing tasks the mandible is displaced forward displacement and rotated around boundary conditions applied along the teeth arch.

Fig. 10 shows the stress distribution along the implanted and the intact mandibles during incisal chewing. The marked anatomical differences between the intact and the implanted mandibles make the quantitative comparison of the observed stresses and strains unfeasible. However, a qualitative comparison is still possible. In the intact mandible, high stress concentrations were observed along the distal temporal crest, posterior aspect ramus, and immediately below the condylar process (Fig. 10 (a)). Very similar stress fields were observed along the implanted model. High stress concentrations were observed along the distal temporal crest with a maximum equivalent stress of approximately $36 \mathrm{MPa}$, on the posterior aspect of the ascending ramus immediately below the condylar process (58 $\mathrm{MPa}$ ), and around the mandibular notch (56 MPa) (Fig. 10 (b)). There is also a less pronounced stress concentration along the lower border of the body immediately anterior to the angle region, which was also observed in the implanted mandible.

The stress patterns observed in both models during right molar and left group clenching were also quite similar. Interestingly, during unilateral clenching high stress values were observed along the ipsilateral oblique line and temporal crest, when compared with the contralateral side. Whereas in the posterior aspect of the ramus, the highest stress values were found along the contralateral ramus, when compared with the working side ramus. The highest stresses were found along the ipsilateral may be a direct consequence of the differences between the ipsilateral and contralateral temporal muscle forces. In right molar function, the right side muscles have comparatively larger craniocaudal components, but the stresses along the posterior border of the right ramus are smaller. The difference is caused mainly due to the

Table 2

Muscle forces for different masticatory activities, namely incisor, right molar and left group clenching.

\begin{tabular}{|c|c|c|c|c|c|c|c|c|c|}
\hline & \multicolumn{3}{|c|}{ Incisal clenching $(\mathrm{N})$} & \multicolumn{3}{|c|}{ Right molar clenching (N) } & \multicolumn{3}{|c|}{ Left group clenching $(\mathrm{N})$} \\
\hline & $\mathrm{x}$ & $\mathrm{y}$ & $\mathrm{z}$ & $\mathrm{x}$ & $\mathrm{y}$ & $\mathrm{z}$ & $\mathrm{x}$ & $\mathrm{y}$ & $\mathrm{z}$ \\
\hline Right masseter & 109.4 & -123.0 & 375.4 & 47.4 & -78.6 & 215.4 & 80.8 & -128.9 & 356.9 \\
\hline Left masseter & 109.4 & 123.0 & 375.4 & 39.4 & 65.5 & 179.5 & 22.3 & 134.1 & 304.8 \\
\hline Right temporalis & -22.0 & -17.0 & 84.3 & -84.0 & -52.6 & 244.3 & -36.3 & -22.5 & 103.7 \\
\hline Left temporalis & -22.0 & 17.0 & 84.3 & -69.2 & 44.3 & 205.6 & -383.2 & 225.4 & 1023.5 \\
\hline Right lateral pterygoid & 203.5 & 183.8 & -32.4 & 19.8 & 16.4 & -4.5 & 49.7 & 44.3 & -8.5 \\
\hline Left lateral pterygoid & 203.5 & -183.8 & -32.4 & 42.8 & -35.6 & -9.8 & 194.8 & -169.5 & -37.3 \\
\hline Right medial pterygoid & 228.9 & 298.2 & 485.3 & 71.2 & 92.8 & 151.0 & 287.4 & 374.5 & 609.5 \\
\hline Left medial pterygoid & 228.9 & -298.2 & 485.3 & 50.9 & -66.3 & 107.8 & 26.5 & -34.5 & 56.1 \\
\hline
\end{tabular}



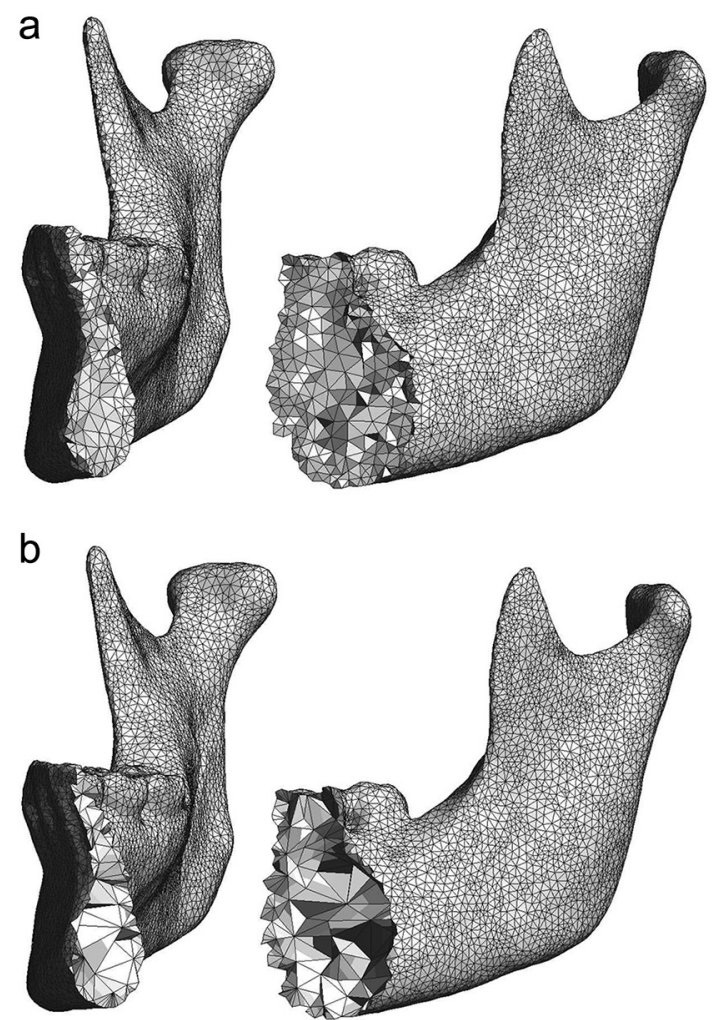

C
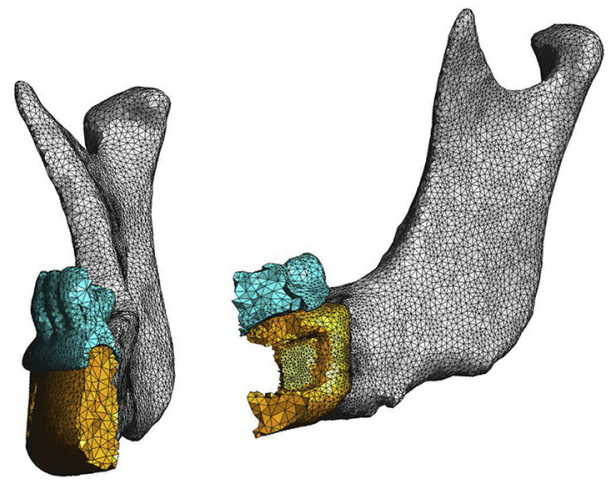

d
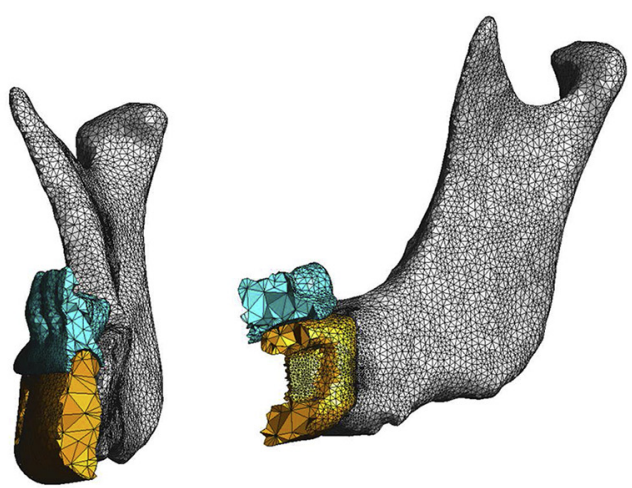

Fig. 7. The model of the intact mandible was used to define the muscle forces for each chewing task: in (a) the Finite Element mesh generated with Simpleware ScanIPT M $+\mathrm{FE}$, and (b) the simplified model for the intact mandible; in (c) the FE mesh of the implanted mandible and in (d) the FE mesh of the implanted mandible after simplification.

increase in third principal stress along the left side of the mandible, comparatively to the right side (working side). In the left group chewing, the masseter and medial pterygoid muscle forces are much larger on the balancing side (especially the right medial pterygoid) than in the working side and this may contribute to the highest compressive stresses observed on the posterior surface of the right ramus.
Regarding the implant, the highest stress concentrations were observed at the implant-screw interface (between the implant and the dental prosthesis), namely 227.3 MPa for incisal chewing, 363.6 MPa for left group clenching, and 124.4 MPa for right molar chewing. However, these maximum stress values are below the fatigue limit for the Ti-6Al-4V alloy (510 MPa). The maximum stress values were found along the working side of the implant. In
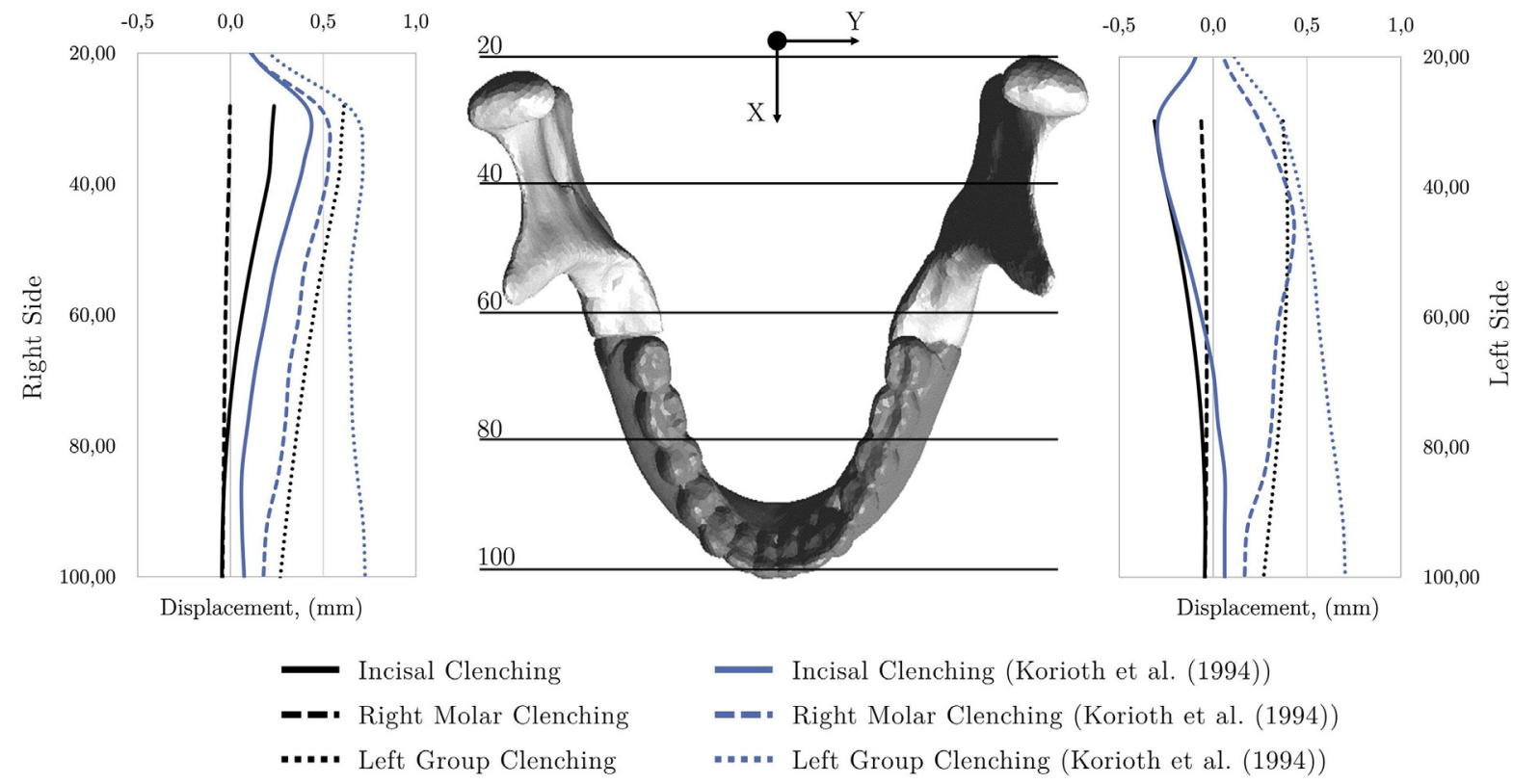

$$
\begin{aligned}
& \text { - Incisal Clenching (Korioth et al. (1994)) } \\
& \text { _- " Right Molar Clenching (Korioth et al. (1994)) } \\
& \text { "..." Left Group Clenching (Korioth et al. (1994)) }
\end{aligned}
$$

Fig. 8. Transverse mandibular displacement during incisal clenching, right molar clenching and left group clenching. 

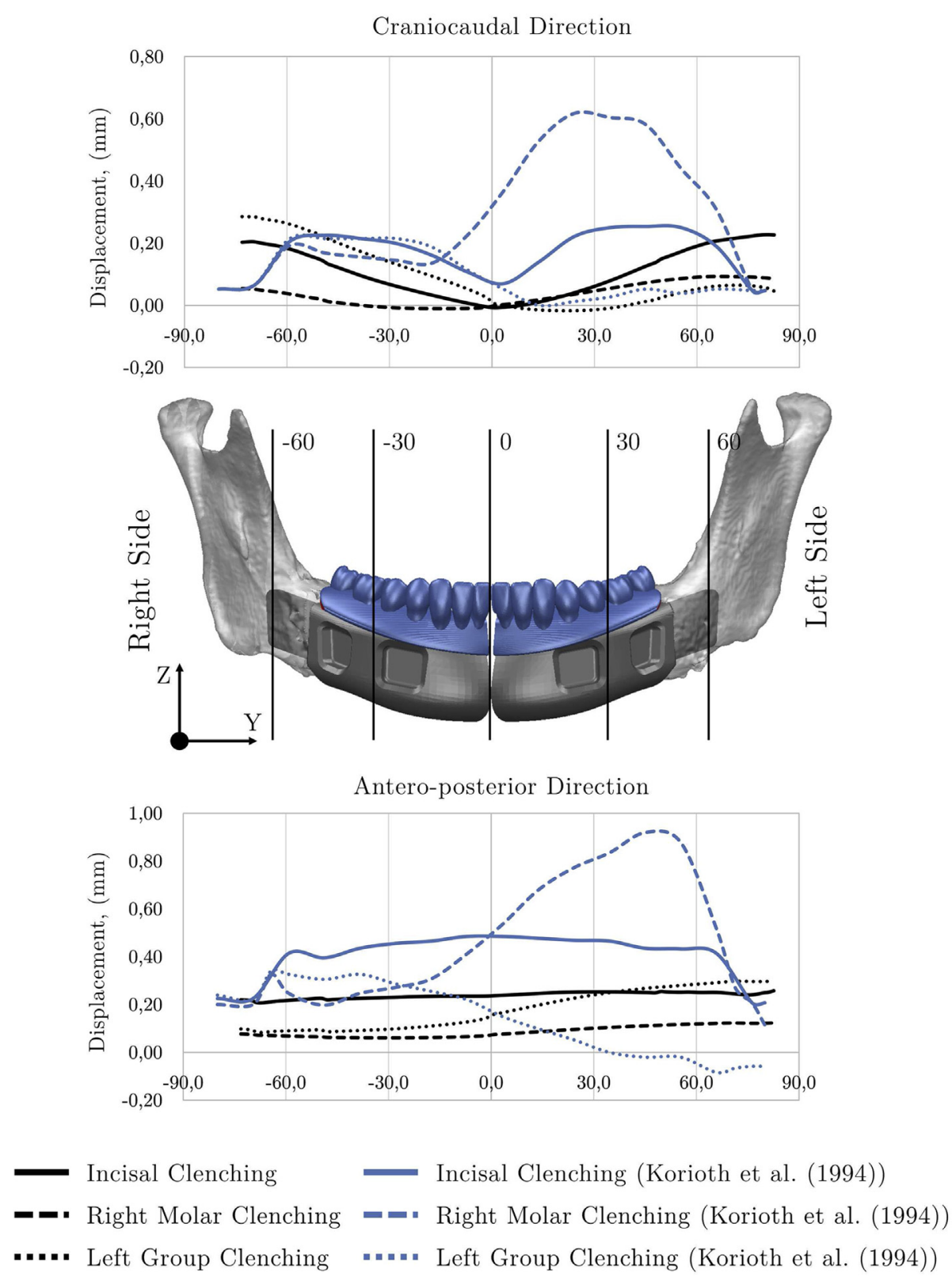

Fig. 9. Craniocaudal and anteroposterior mandibular displacement during incisal clenching, right molar clenching and left group clenching tasks.

addition, the posterior aspect of the implant was more critically loaded than the anterior aspect, and the equivalent stresses decreased gradually towards the chin (Fig. 10). Excluding the implant-screw interface, the maximum stresses along the implant body for incisal, right molar, and left group chewing were $92.1 \mathrm{MPa}$ on the buccal side, $40.3 \mathrm{MPa}$ on the lingual aspect, and $96.5 \mathrm{MPa}$ also on the lingual aspect of the implant, respectively.

The strain distribution along the bone-implant interface is thought to play a paramount role in the bone remodelling process, and consequently in the achievement of a rigid and durable fixation to the host bone (Simmons et al., 2001a,b; Jokstad, 2009). Fig. 11 shows the superficial von Mises equivalent strains along the bone-implant interface for the three chewing tasks. High strain values were observed in the upper and lower border of the implant's stems.
During incisal clenching similar equivalent strain fields were observed on the left and the right sides of the implant's surface. Equivalent strains were higher along the outer upper border and the lower inner border of the bone-implant interface. Strain gradually decreased towards the centre of each stem, as shown in Fig. 11 (a). The superficial equivalent strains on the two implant stems ranged from $41.10 \mu$ strains up to $3028.50 \mu$ strains. Equivalent strains higher than $200 \mu$ strains (the threshold thought to trigger bone resorption) were observed on $63 \%$ of their surface area. For right molar clenching the highest strain deformations were found on the balancing side (Fig. 11 (b)). The equivalent strains observed along the bone-implant interface ranged from $3.4 \mu$ strains to 849.6 $\mu$ strains, but only $8 \%$ of them were above $200 \mu$ strains. Likewise, during left group chewing the highest von Mises strains were observed on the right side of the stem (Fig. 11 (c)). Equivalent 

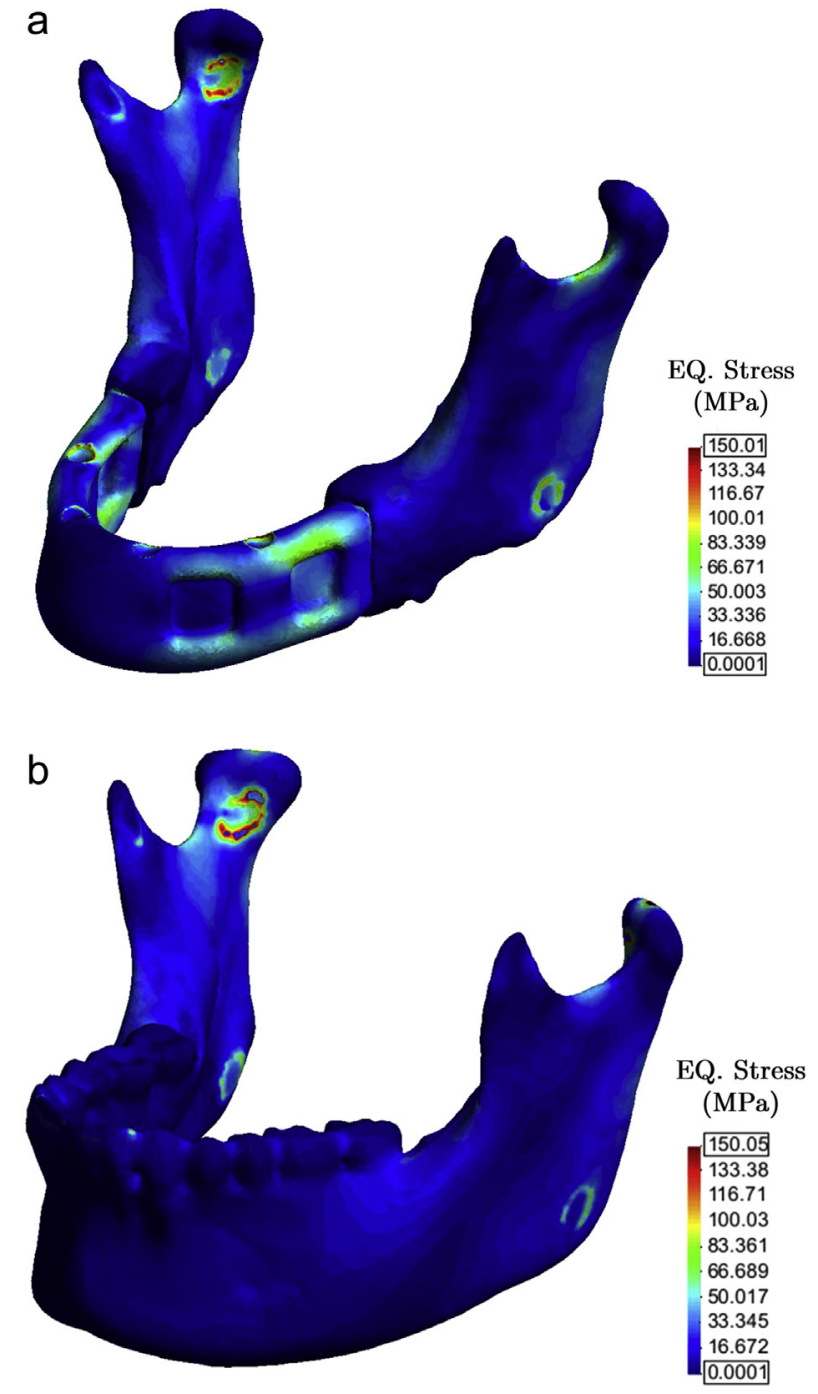

Fig. 10. Equivalent von Mises stress distribution along the implanted right and left mandibular segments in (a) and along the intact mandible in (b) for incisal clenching.

strains up to from $3283.50 \mu$ strains were observed and $77 \%$ of the interfacial strains were above the $200 \mu$ strains.

\section{Discussion}

In this work, a procedure for custom mandibular reconstruction, whether with the standard free microvascular fibular flap or by a solid mandibular endoprosthesis, was proposed. The mandibular endoprosthesis was tested under three clenching tasks. Recently, several authors support the idea that mastication is carried by groups of teeth rather than independently by each tooth (Oosterhaven et al., 1988; Fontijn-Tekamp et al., 2000; Ichim et al., 2006), and therefore multiple teeth chewing was simulated.

Due to the absence of any prior geometrical information about the intact mandible, an intact mandible obtained from elsewhere was used to determine the muscle forces needed to produce the desired masticatory forces along the teeth arch. The use of different intact and implanted mandibular models restricts the analysis of the FE results. The mandibular shape and the localized variations of cortical thickness seem to influence the strain distribution along the mandible (Daegling and Hylander, 1998; Van Eijden, 2000; Meyer et al., 2002). Therefore, the direct (quantitative) comparison of the stresses and strains observed along the intact and implanted mandibles may be unfeasible, due to their marked morphological differences (see for instance Fig. 7).

In Korioth and Hannam (1994) conducted an extensive analysis over the displacements of the intact Human mandible during different chewing tasks. For incisal clenching, it was observed a posterior compression of the mandible and a slight rotation towards the left side along the transverse plane. The nodal displacements obtained with the mandibular implant show that this behaviour can be recovered. Ideally, the equal bilateral recruitment of the different muscle fibres should produce a symmetrical (sagittal) displacement of the mandible. The slight asymmetrical displacement fields observed may be an evidence of the existence of an asymmetry in the reconstructed mandible, which may also contribute to a slight asymmetrical loading of the implant.

The anterior and vertical displacements after implantation also correlate well with the observations in Korioth and Hannam (1994). For right molar chewing, Korioth and Hannam (1994) observed a global displacement towards the balancing along the transverse plane of the mandible. The anterior and vertical displacements were more pronounced in the left (balancing) side when compared with the working side. In the intact mandible (used to generate the desired bite forces), the displacement fields are in agreement with these previous observations. However, with the mandibular endoprosthesis, a residual transverse displacement towards the right side was observed on both sides of the implanted mandible, instead of the outward displacement towards the balancing side (Fig. 8). Implant stiffness may lead the forces produced by right masseter, right temporalis, left lateral pterygoid and left medial pterygoid muscles in this direction to slightly overcome to the outward pull on the balancing side forces, leading to the global rotation to the right side. In contrast, the displacement fields of the implanted mandible in the anteroposterior and craniocaudal direction were similar to the patterns found in the intact mandible (Fig. 9). The displacement fields of the implanted mandible in the antero-posterior and craniocaudal direction were similar to the patterns found in the intact mandible, with the exception for the anterior displacement during left group chewing (Fig. 9). During left group chewing, the mandible was transversely displaced towards the working side, the anterior displacements were higher on the working side. For left group clenching, Korioth and Hannam (1994) observed that higher anterior displacements should occur along the balancing side. The results obtained are a consequence of the inward pull of the right medial Pterygoid, which causes the mandibular implant to rotate around itself towards the right side. For this task higher vertical displacements were observed on the right side of the mandibule, which is in agreement with the observations of Korioth and Hannam (1994).

For incisal clenching, the nodal displacement fields show an inward rotation along the anteroposterior direction ( $\mathrm{x}$-axis), where the teeth arch is mainly under compression. The mandible is also rotated forward (along y-direction). During right molar clenching, the mandible is mainly rotated towards the right (around the $\mathrm{x}$ axis), whereas in left group function the mandible is rotated towards the left side in the craniocaudal direction and along the $\mathrm{x}-$ axis. The deformation fields observed along the implanted mandible show that it mainly rotates around the boundary conditions imposed along the dental arch. These displacement fields are in agreement with the predictions in Hylander et al. (1987) and Korioth and Hannam (1994) for the intact mandible. Therefore, the proposed mandibular lapantim seems to restore (with the exception of the anterior displacements for left group chewing) the natural displacement fields along the intact mandible. 

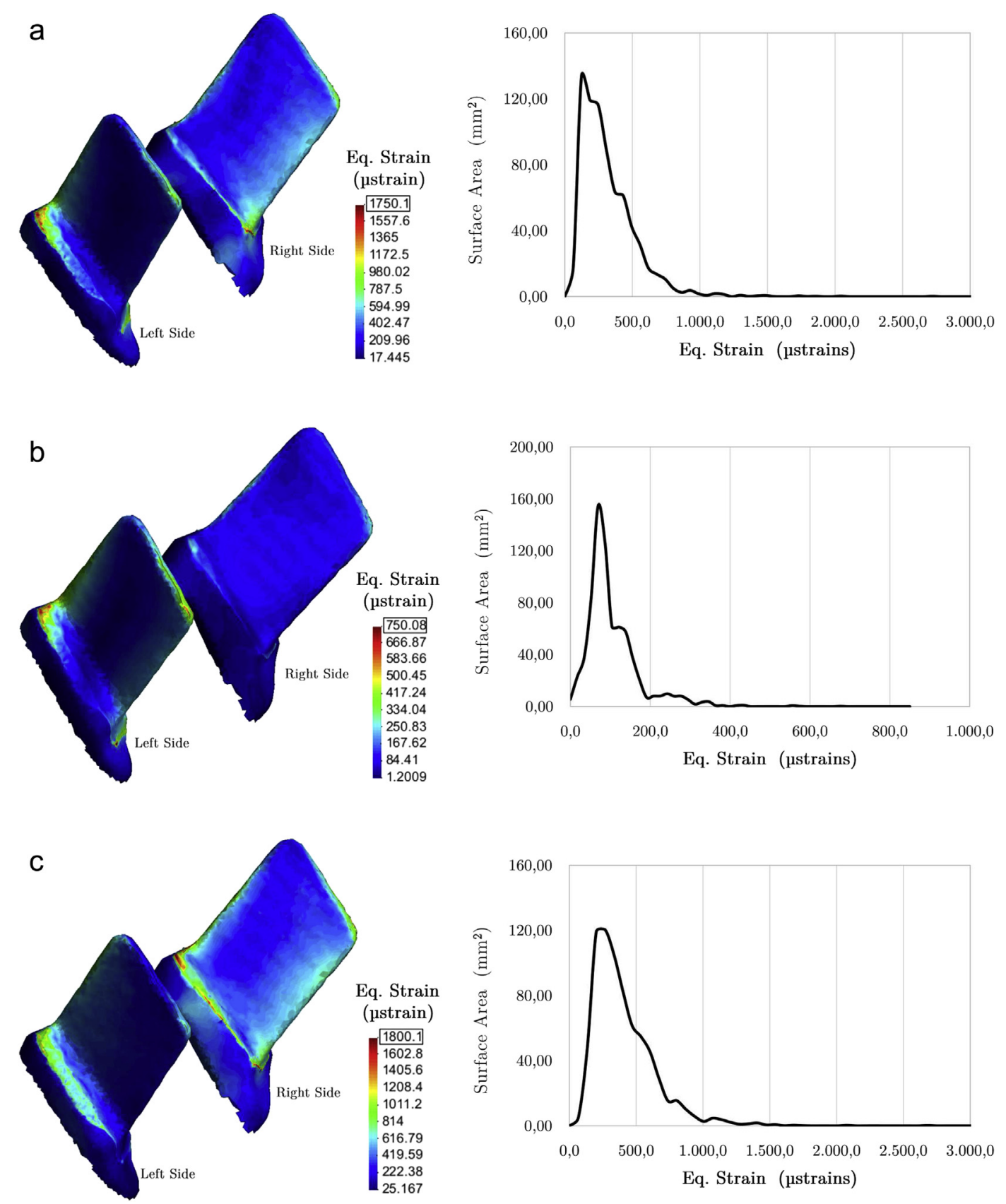

Fig. 11. Equivalent strain deformation along the bone-implant interface for incisal biting (a), right molar clenching (b), and left group biting (c).

Similar stress fields were observed for both intact and implanted mandibles (Fig. 10). This suggests that the proposed mandibular endoprosthesis allows the preservation of the normal stress distribution along the right and left mandibular segments. In addition, the proposed solid mandibular endoprosthesis showed no signs of mechanical failure, nor reduced stiffness as previously reported by other authors (Wong et al., 2012b). The results obtained show that stress distributions in the mandible are complex, and slightly different depending on the chewing task. In incisal clenching, stress concentrations were observed mainly along the distal temporal crest, the posterior aspect of the ascending ramus, the mandibular notch, and in the lower and lingual surface of the mandible immediately anterior to the mandible angle. These stress fields are consistent with the results obtained in Meyer et al. (2002) with photoelastic analysis.
For unilateral clenching, high stress concentrations were observed on the ipsilateral temporal crest and contralateral proximal posterior ramus. Stress concentrations along mandibular body of the working side and posterior mandibular ramus of the balancing side have been previously observed in Wang et al. (2010) for left unilateral chewing. The highest stresses along the mandibular implant were also observed at the implant-screw interface, nevertheless these stresses were always below the fatigue limit of the Ti-6Al-4V alloy considered for implant manufacturing. In addition, the mandibular endoprosthesis also avoids using screwed connections that have been associated with unfavourable stress concentrations along the mandibular bone, implant loosening and implant and screw fracture by several authors (Kim and Donoff, 1992; Spencer et al., 1999; Shibahara et al., 2002; Knoll et al., 2006; Ramos et al., 2011; Narra et al., 2014). 
The endoprosthesis concept was successfully applied in Lee et al. (2008) and in Goh et al., (2009b) for the reconstruction of the mandibular body and unilateral reconstruction of the ascending ramus. In a histological evaluation of a cemented modular mandibular endoprosthesis 6 months after implantation, Lee et al. (2009) found no signs of loosening and the radiological evaluation revealed a stable position of the implant. It was also observed an increase of woven bone volume around the implant stems, particularly along the inferior and lingual aspects of the implant stems. In addition, the histological evaluation of the endoprosthesis applied to the ramus 3 and 6 month after implantation showed an overall increase of the bone volume around the implant's stem (Goh et al., 2009a), and a residual bone mass density loss of $1.8 \%-5.8 \%$ were observed around the implant (Goh et al., 2010). Nearly complete bone union and bone ingrowth were observed in Chanchareonsook et al. (2014) with an hydroxyapatite-coated custom modular endoprosthesis implanted in monkeys after 6 months follow-up.

In this work high strain values were observed not only on the inferior and lingual regions of the stems, but also on the buccal and superior aspects, especially on the balancing side during unilateral chewing. In addition, the strain deformations along the implant stems showed that $63 \%$ and $77 \%$ of the implant-bone interface experience strains above $200 \mu$ strains during incisal and left group clenching, which is thought to be the physiological threshold to trigger bone maintenance and remodelling. Nevertheless, a smaller and less stiff implant may be advantageous to reduced strain shielding around the implant-bone interface. For dental prosthesis-implant interface, a four dental implant system was considered. This system seems to be unsuitable for transmitting distal teeth chewing forces to the supporting bone. A different type of implant-dental prosthesis interface, such as a solid interface or a screwed interface with more distal screws should be considered in the future, to improve bone loading during right molar loading (Fig. 11).

The results obtained for the mandibular endoprosthesis are very encouraging. However, these results may be affected by the simplifications on the FE model. In this study, all materials in the FE model were assumed to be isotropic and homogeneous. Ichim et al. (2006) argued that modelling the Human mandible as an isotropic material was sufficient to obtain meaningful physiological strain variations during different chewing tasks. However, it is known that the Human mandible is more accurately modelled as an anisotropic (Ashman et al., 1984; Dechow et al., 1993), or a transversely isotropic material (Hart et al., 1992; Van Eijden, 2000), and that it may be highly heterogeneous due to the variations of cortical thickness along the different anatomical regions (Daegling and Hylander, 1998). The muscle insertion areas in the FE model are also a simplification of the real insertion areas. For instance, the masseter muscles occupy almost all the lateral surface of the ascending ramus. The high stress concentrations at the muscle insertion sites and smaller stresses along the inner aspect of the ramus (in both intact and implanted mandibles) may be unrealistic.

The implant and the bone are also assumed to be perfectly bounded. Immediately after insertion there is always a certain amount of relative movement between the two bodies. The existence of micro-motions along the bone-implant interface, at this early stage, may compromise bone ingrowth into the implant, and in the long term lead to implant loosening, particularly in cementless designs such as the one proposed here. Interfacial micro-motions above $150 \mu \mathrm{m}$ seem to inhibit bone ingrowth into the implant (Pilliar et al., 1986; Jasty et al., 1997). Hence, to predict more reliably the behaviour of the mandibular endoprosthesis invivo, a more realist model may be needed. The implant is also clearly over-dimensioned and the reduction of the implant's stiffness may be important to obtain a more natural deformation of the mandible, and promote a more favourable environment for implant osseointegration. Reducing the implant's cross-section to a simple titanium core capable to sustain the different chewing tasks, and the addition of other non-metallic features to obtain the desired mandibular shape defined in the cephalometric assessment, or the addition of other geometrical features to this design may be possible solutions.

\section{Conclusions}

In this work a custom-made mandibular endoprosthesis to bridge a major mandibular defect is proposed. A cephalometric analysis was applied to estimate the most plausible position of the chin along the sagittal plane. The geometrical and anatomical relations between the maxilla and the mandible, as well as the lower arch teeth, were considered in the project phase in order to guarantee the functional and aesthetic outcome of the mandibular reconstruction. The custom-made implant also aims to avoid the application of screws, since these features are commonly associated with unnatural stress fields along the mandible and with implant failure.

The newly designed implant was validated with Finite Element Analysis under three clenching tasks, namely incisal, right molar and left group clenching. The implanted mandible shows displacement fields that are similar to the displacement patterns observed for intact mandibles. The stress fields observed along the two mandibular segments also correlate well with the stress distributions observed for the intact mandible. The strain values at the implant-bone interface may also promote bone preservation and ingrowth around the implant. These preliminary results show that these implants may be a reliable alternative to other prosthetic mandibular reconstruction approaches.

\section{Conflict of interest statement}

The authors declare that there are no conflicts of interest.

\section{Acknowledgment}

The first author would like to acknowledge FCT Fundação para a Ciência e Tecnologia (Portugal) for the PhD grant SFRH/BDE/51143/ 2010. The authors also would like to acknowledge MCM - Mario da Costa Martins \& Filho Lda. for all technical support provided during this work.

\section{References}

Ashman R, Cowin S, Van Buskirk W, Rice J: A continuous wave technique for the measurement of the elastic properties of cortical bone. J Biomech 17: 349-361, 1984

Athanasiou AE: Orthodontic cephalometry. Mosby-Wolfe, 1995

Baggi L, Cappelloni I, Di Girolamo M, Maceri F, Vairo G: The influence of implant diameter and length on stress distribution of osseointegrated implants related to crestal bone geometry: a three- dimensional finite element analysis. J Prosthet Dent 100: 422-431, 2008

Bak M, Jacobson AS, Buchbinder D, Urken ML: Contemporary reconstruction of the mandible. Oral Oncol 46: 71-76, 2010

Bozkaya D, Muftu S, Muftu A: Evaluation of load transfer characteristics of five different implants in compact bone at different load levels by finite elements analysis. J Prosthet Dent 92: 523-530, 2004

Chanchareonsook N, Tideman H, Feinberg SE, Jongpaiboonkit L, Lee S, Flanagan C, et al: Segmental mandibular bone reconstruction with a carbonate- substituted hydroxyapatite-coated modular endoprosthetic poly ( $\varepsilon$-caprolactone) scaffold in macaca fascicularis. J Biomed Mater Res B Appl Biomater 102: 962-976, 2014

Cobourne M, DiBiase A: Handbook of orthodontics. Elsevier Health Sciences UK, 2010

Daegling DJ, Hylander WL: Biomechanics of torsion in the human mandible. Am J Phys Anthropol 105: 73-88, 1998

Dechow P, Nail G, Schwartz-Dabney C, Ashman R: Elastic properties of human supraorbital and mandibular bone. Am J Phys Anthropol 90: 291-306, 1993 
Disa JJ, Cordeiro PG: Mandible reconstruction with microvascular surgery. In: Library WO (ed.), Semin Surg Oncol. Wiley Online Library, 226-234, 2000

Ferrario V, Sforza C, Serrao G, Dellavia C, Tartaglia G: Single tooth bite forces in healthy young adults. J Oral Rehabil 31: 18-22, 2004

Ferri J, Piot B, Ruhin B, Mercier J: Advantages and limitations of the fibula free flap in mandibular reconstruction. J Oral Maxillofac Surg 55: 440-448, 1997

Flint P, Haughey B, Niparko J, Richardson M, Lund V, Robbins K, et al. Cummings otolaryngology - head and neck surgery, 3-volume set, vol. 1. Elsevier Health Sciences, 2010

Fontijn-Tekamp F, Slagter A, Van Der Bilt A, Hof MV, Witter D, Kalk W, et al: Biting and chewing in overdentures, full dentures, and natural dentitions. J Dent Res 79: 1519-1524, 2000

Goh BT, Lee S, Tideman H, Jansen JA, Stoelinga PJ: Replacement of the condyle and ascending ramus by a modular endoprosthesis in macaca fascicularis part 2: microcomputed tomographic and histologic evaluation of the ramus and stem. J Oral Maxillofac Surg 67: 2617-2626, 2009a

Goh BT, Lee S, Tideman H, Stoelinga PJ: Mandibular reconstruction in adults: a review. Int J Oral Maxillofac Surg 37: 597-605, 2008

Goh BT, Lee S, Tideman H, Stoelinga PJ: Replacement of the condyle and ascending ramus by a modular endoprosthesis in macaca fascicularis part 1: a clinical and radiographic study. J Oral Maxillofac Surg 67: 1392-1400, 2009b

Goh BT, Lee S, Tideman H, Stoelinga PJ, Jansen JA: Replacement of the condyle and ascending ramus by a modular endoprosthesis in macaca fascicularis part 3 : evaluation of peri-implant bone remodeling. J Oral Maxillofac Surg 68: 1776-1782, 2010

Gurtner GC, Evans GR: Advances in head and neck reconstruction. J Oral Maxillofac Surg 106: 672-682, 2000

Hart RT, Hennebel VV, Thongpreda N, Van Buskirk WC, Anderson RC: Modeling the biomechanics of the mandible: a three-dimensional finite element study. J Biomech 25: 261-286, 1992

Haughey BH, Fredrickson JM, Lerrick AJ, Sclaroff A, Gay WD: Fibular and iliac crest osteomuscular free flap reconstruction of the oral cavity. Laryngoscope 104: 1305-1313, 1994

Hidalgo DA: Fibula free flap: a new method of mandible reconstruction. Plast Reconstr Surg 84: 71-79, 1989

Hilgers ML, Scarfe WC, Scheetz JP, Farman AG: Accuracy of linear temporomandibular joint measurements with cone beam computed tomography and digital cephalometric radiography. Am J Orthod Dentofacial Orthop 128: 803-811, 2005

Hylander WL, Johnson KR, Crompton A: Loading patterns and jaw movements during mastication in macaca fascicularis: a bone-strain, electromyographic, and cineradiographic analysis. Am J Phys Anthropol 72: 287-314, 1987

Ichim I, Swain M, Kieser J: Mandibular biomechanics and development of the human chin. J Dent Res 85: 638-642, 2006

Jackson J: A user's guide to principal components. Wiley, 2005 Wiley Series in Probability and Statistics

Jasty M, Bragdon C, Burke D, O'Connor D, Lowenstein J, Harris WH: In vivo skeletal responses to porous-surfaced implants subjected to small induced motions. J Bone Joint Surg 79: 707-714, 1997

Jokstad A: Osseointegration and dental implants. John Wiley \& Sons, 2009

Kawashima S, Peltomaki T, Sakata H, Mori K, Happonen RP, Ronning O: Craniofacial morphology in preschool children with sleep-related breathing disorder and hypertrophy of tonsils. Acta Paediatr 91: 71-77, 2002

Kim MR, Donoff RB: Critical analysis of mandibular reconstruction using ao reconstruction plates. J Oral Maxillofac Surg 50: 1152-1157, 1992

Knoll WD, Gaida A, Maurer P: Analysis of mechanical stress in reconstruction plates for bridging mandibular angle defects. J Craniomaxillofac Surg 34: 201-209, 2006

Korioth T, Hannam A: Deformation of the human mandible during simulated tooth clenching. J Dent Res 73: 56-66, 1994

Lagravère MO, Hansen L, Harzer W, Major PW: Plane orientation for standardization in 3- dimensional cephalometric analysis with computerized tomography imaging. Am J Orthod Dentofacial Orthop 129: 601-604, 2006

Lee S, Goh B, Tideman H, Stoelinga P: Modular endoprosthesis for mandibular reconstruction: a preliminary animal study. Int J Oral Maxillofac Surg 37: 935-942, 2008

Lee S, Goh B, Tideman H, Stoelinga P, Jansen J: Modular endoprosthesis for mandibular body reconstruction: a clinical, micro-ct and histologic evaluation in eight macaca fascicularis. Int J Oral Maxillofac Surg 38: 40-47, 2009

Li P, Shen L, Li J, Liang R, Tian W, Tang W: Optimal design of an individual endoprosthesis for the reconstruction of extensive mandibular defects with finite element analysis. J Craniomaxillofac Surg 42: 73-78, 2014

Maló P, Rangert B, Nobre M: All-on-four immediate-function concept with Branemark system ${ }^{\circledR}$ implants for completely edentulous mandibles: a retrospective clinical study. Clin Implant Dent Relat Res 5: 2-9, 2003

Maló P, Rangert B, Nobre M: All-on-4 immediate-function concept with Branemark system $^{B}$ implants for completely edentulous maxillae: a 1 -year retrospective clinical study. Clin Implant Dent Relat Res 7: s88-s94, 2005

Meneghini F, Biondi P: Clinical facial analysis: elements, principles, and techniques. Springer Berlin Heidelberg, 2012

Meyer C, Kahn JL, Boutemi P, Wilk A: Photoelastic analysis of bone deformation in the region of the mandibular condyle during mastication. J Craniomaxillofac Surg 30: 160-169, 2002

Miloro M, Ghali G, Larsen P, Waite P. Peterson's principles of oral and maxillofacial surgery, vol. 1. B C Decker, 2004
Misch CE: Contemporary implant dentistry. Elsevier Health Sciences, 2007

Mitchell L: An introduction to orthodontics. OUP Oxford, 2013

Moorrees CF, Kean MR: Natural head position, a basic consideration in the interpretation of cephalometric radiographs. Am J Phys Anthropol 16: 213-234, 1958

Narra N, Valášek J, Hannula M, Marcián P, Sandor GK, Hyttinen J, et al: Finite element analysis of customized reconstruction plates for mandibular continuity defect therapy. J Biomech 47: 264-268, 2014

Nickels L: World's first patient-specific jaw implant. Metal Powder Rep 67: 12-14 2012

Oliveira M, Alves J, Menezes L: Algorithms and strategies for treatment of large deformation frictional contact in the numerical simulation of deep drawing process. Arch Computational Methods Eng 15: 113-162, 2008

Oosterhaven SP, Westert GP, Schaub RM, Bilt A: Social and psychologic implications of missing teeth for chewing ability. Community Dent Oral Epidemiol 16: 79-82, 1988

Östrup LT, Fredrickson JM: Reconstruction of mandibular defects after radiation, using a free, living bone graft transferred by microvascular anastomoses: an experimental study. Plast Reconstr Surg 55: 563-572, 1975

Peckitt N: Stereoscopic lithography: customized titanium implants in orofacial reconstruction. Br J Oral Maxillofac Surg 37: 353-369, 1999

Peled M, El-Naaj IA, Lipin Y, Ardekian L: The use of free fibular flap for functional mandibular reconstruction. J Oral Maxillofac Surg 63: 220-224, 2005

Pilliar R, Lee J, Maniatopoulos C: Observations on the effect of movement on bone ingrowth into porous-surfaced implants. Clin Orthop Relat Res 208: 108-113, 1986

Pinheiro M, Alves J: A new level-set based protocol for accurate bone segmentation from ct imaging, http://arxiv.org/abs/1505.03093; Submitted

Proffit W, Fields H, Sarver D: Contemporary orthodontics. Elsevier Health Sciences, 2006

Ramos A, Completo A, Relvas C, Mesnard M, Simoes J: Straight, semi-anatomic and anatomic TMJ implants: the influence of condylar geometry and bone fixation screws. J Craniomaxillofac Surg 39: 343-350, 2011

Samman N, Luck W, Cheung L, Tideman H, Clark R: Custom-made titanium mandibular reconstruction tray. Aust Dent J 44: 195-199, 1999

Sato K, Shirakawa T, Sakata H, Asanuma S: Effectiveness of the analysis of craniofacial morphology and pharyngeal airway morphology in the treatment of children with obstructive sleep apnoea syndrome. Dentomaxillofac Radiol 41 411-416, 2012

Shibahara T, Noma H, Furuya Y, Takaki R: Fracture of mandibular reconstruction plates used after tumor resection. J Oral Maxillofac Surg 60: 182-185, 2002

Simmons CA, Meguid SA, Pilliar RM: Differences in osseointegration rate due to implant surface geometry can be explained by local tissue strains. J Orthop Res 19: 187-194, 2001a

Simmons CA, Meguid SA, Pilliar RM: Mechanical regulation of localized and appositional bone formation around bone-interfacing implants. J Biomed Mater Res 55: 63-71, 2001b

Singare S, Dichen L, Bingheng L, Yanpu L, Zhenyu G, Yaxiong L: Design and fabrication of custom mandible titanium tray based on rapid prototyping. Med Eng Phys 26: 671-676, 2004

Singh G: Textbook of orthodontics. G - reference, information and interdisciplinary subjects series. Jaypee Brothers, Medical Publishers, 2008

Skedros J, Mason M, Nelson M, Bloebaum R: Evidence of structural and material adaptation to specific strain features in cortical bone. Anat Rec 246: 47-63, 1996

Spencer K, Sizeland A, Taylor G, Wiesenfeld D: The use of titanium mandibular reconstruction plates in patients with oral cancer. Int J Oral Maxillofac Surg 28: 288-290, 1999

Taylor GI: Reconstruction of the mandible with free composite iliac bone grafts. Ann Plast Surg 9: 361-376, 1982

Tideman H, Lee S: The TL endoprosthesis for mandibular reconstruction a metallic yet biological approach. J Oral Maxillofac Surg Med Pathol 18, 2006

Van Eijden T: Biomechanics of the mandible. Crit Rev Oral Biol Med 11: 123-136, 2000

Van Oosterwyck H, Duyck J, Vander Sloten J, Van der Perre G, De Coomans M, Lieven S, et al: The influence of bone mechanical properties and implant fixation upon bone loading around oral implants. Clin Oral Implant. Res 9: 407-418, 1998

Waltimo A, Kemppainen P, Könonen M: Maximal contraction force and endurance of human jaw-closing muscles in isometric clenching. Eur J Oral Sci 101: 416-421, 1993

Wang H, Ji B, Jiang W, Liu L, Zhang P, Tang W, et al: Three-dimensional finite element analysis of mechanical stress in symphyseal fractured human mandible reduced with miniplates during mastication. J Oral Maxillofac Surg 68: 1585-1592, 2010

Welsch G, Boyer R, Collings E: Materials properties handbook: titanium alloys. ASM International, 1993

Wong RC, Tideman H, Merkx MA, Jansen J, Goh SM: The modular endoprosthesis for mandibular body replacement. Part 1: mechanical testing of the reconstruction. J Craniomaxillofac Surg 40: 479-486, 2012a

Wong RC, Tideman H, Merkx MA, Jansen J, Goh SM: The modular endoprosthesis for mandibular body replacement. Part 2: finite element analysis of endoprosthesis reconstruction of the mandible. J Craniomaxillofac Surg 40: 487-497, 2012b

Yáñez-Vico RM, Iglesias-Linares A, Torres-Lagares D, Gutiérrez-Pérez JL, Solano-Reina E: Three-dimensional evaluation of craniofacial asymmetry: an analysis using computed tomography. Clin Oral Investig 15: 729-736, 2011 